\title{
Analysis of How Capstone Teams Define Engineering DESIGN FAILURE
}

\author{
Farrah Fayyaz \\ Concordia University, Montreal \\ farrah.fayyaz@concordia.ca
}

\begin{abstract}
There is a growing trend in engineering education to increase the societal awareness among the engineering graduates, so that the engineering solutions proposed by the engineers are more sustainable. To achieve this, one of the efforts in Concordia University is to ask capstone students to discuss and implement (wherever possible) ethical, legal, social, environmental, and entrepreneurial aspects of their capstone design. Students are given two lectures during the capstone year which provides them with prompts to identify and think beyond their personal biases and perceptions of the society. At the end of the term, each capstone team is asked to define engineering failure. The aim for this is for graduating students to have a well thought of idea of the engineering design failure before they enter the workplace. This article explains the two phases (lectures) of the capstone lectures related to the ethical, legal, societal, environmental, and entrepreneurial aspects of an engineering design. Additionally, the article aims to analyze the definitions of engineering failure submitted by the engineering students at the end of the capstone year to identify keywords and terms that the graduating engineering students attribute to success and failure of an engineering design. The objective of the paper is to open the discussion among engineering educators for incorporating ideas in their courses that can improve engineering students' understanding of a sustainable design and assess the success of these strategies
\end{abstract}

Keywords: Capstone design, societal implications, critical reflection, professional skills.

\section{INTRODUCTION}

Currently, there is an increasing need and discussion around engineering education research to find ways to guide our graduating engineers to become more and more aware of the complicated relationship between science and society. Society calls for innovation (problem finding) and in turn, engineers and technologists provides solutions and remake society (problem finding), and the cycle of "coproduction" continues [1]. Traditionally, educators have focused more on teaching problem solving as compared to problem finding [2]. With the improvement in the understanding of societal linkages with the technology, the hope is that the graduating engineers will have increased ability to find problems and to provide more sustainable solutions. However, there are numerous challenges in achieving the goal to train our graduating engineers to have a deeper understanding of various societal intricacies and industrial needs in addition to sound technical knowledge. For example, just identifying the societal needs and concerns can get very complicated as these perspectives are very much dependent on the perspective of the person analyzing or describing a given situation $[3,4]$. Additionally, the continued rapid change and growth of advancements in science and technology, continuously present challenging situations to engineers related to ethics and values [5]. There is not enough research yet to understand how engineering students engage in the ethicaldecision making, hence the solutions are not very developed yet [6]. Furthermore, there is limited space in the engineering curriculum to incorporate and reinforce the professional skills that are not only important for the engineering development and sustainability but also required by the accrediting bodies in many countries. Capstone courses are great opportunities to train students to understand and deal with real-world challenges beyond just technical skills [7]. At Concordia University, along with including the discussions of ethical, legal, social, environmental, and entrepreneurial/economical issues related to an engineering design in various technical and communication courses, we are using the capstone courses as an opportunity to hammer the awareness and sensitivity towards analysis and inclusion of all these issues in an engineering design as at the capstone stage most teams work on solving some form of real-world issues. This article describes the work that is currently being done at Concordia University. This work is still in its infancy and one of the ideas behind sharing this is to get feedback from engineering educators working on similar ideas and also identify possibilities of collaborations across other engineering schools all over Canada. The article concludes with the discussion of the impact that is being observed in graduating students' thinking and design as a result of this activity. 


\section{WHAT "ELSEE" ARE WE DOING AT CONCORDIA UNIVERSITY}

Exploiting Guston and Sarewitz's model of real time assessment of technology [1], a model is developed at Concordia University to help graduating engineering students to understand and anticipate societal impact of their capstone project. This includes short term impact (that is, given the resources and scope of the capstone itself) and long term impact (if the students see or hope further growth in their project and given there are more resources available in the future to further enhance the design).

Main skills focused in this exercise are the following professional skills related graduate attributes: Communication skills (mostly listening and talking to experts and stakeholders); professionalism; impact of engineering on society and the environment; ethics and equity; economics and project management; and lifelong learning. The acronym ELSEE is used to represent the Ethical, Legal, Social, Environmental, Economical/Entrepreneurial aspects.

The complete process involves six tasks. The first three tasks are completed in the first semester during the design phase and the last three tasks are completed in the second semester. Here is the detail of each task:

\subsection{Phase 1 - Research}

Phase 1 is conducted in the first semester of the capstone project during the design phase. The idea is that in addition to conducting the traditional style research on the latest technological trends and technology related experts' practices, students are also expected to conduct research to identify as much as possible, all the ELSEE issues related to their field of design and ELSEE related experts' practices. Each capstone team meets with the author at least once during Phase 1 to explain all possible ELSEE aspects related to their project that they have researched and discuss any challenges they are facing in this research. Since all capstone projects are different, the discussions are done on one-on-one basis, so each team can be guided towards the right direction as per the scope of their project. Acknowledging the fact that the students are in engineering program and not social science majors, they are encouraged to gather as much information as possible related to ELSEE, but they are not forced to bring to the table all the possible information and social theories out there. At the end of the semester students write about the information researched in their mid-term capstone report. The three research related tasks that the students are expected to do in Phase 1 are as follows:

\section{Task \# 1 - Identify stakeholders}

To be able to understand the societal impact of the engineering product, the first step is to understand what stakeholders are potentially impacted by it. To help engineering students identify the stakeholders, an altered version of Simoni and Andrijcic's framework to identify and define the stakeholders is used [3]. In this task, students are asked to not just identify the stakeholders of the project, but also define them, so they have a clear picture of the impact. For example, if the capstone design is a multistorey condo building, the neighbors are one of the stakeholders. However, depending on the project, it might not be possible to put all neighbors in one category, because the neighboring schools may have different expectations or requirements as compared to businesses in the neighbor, etc. This means that in addition to identifying all societal stakeholders, students are also encouraged to define, and rank (in the level of importance) all related stakeholders including government, policy makers, legislators, etc. These include people or organizations that are dissatisfied with the current situation, that are affected by changing the situation, that will authorize the change in the situation, that benefit from a project similar to theirs, that benefit from no solution being enacted, that are affected if there is a failure to enact the solution, that are affected if students' design fails, etc. This exercise pushes students to explore the complexity and diversity of various actors in society rather than treating society as a "black box". Students are mainly expected to brain storm among themselves to identify and define stakeholders.

\section{Task \# 2 - Listen to the stakeholders}

For this task, students are asked to (1) find (in research articles, news, reliable discussion forums, interviews, etc.) real life engineering failure stories related to projects similar to theirs and (2) research on the details of the societal impact as a result of the failure, for example, as a result of an engineering failure, who got affected, who filed the complaint (if the complaint was ever filed), what happened after the complaint, who was declared to be at fault, etc.

It is important to note here that students are asked to analyze and discuss these situations without adding any opinion of their own (that is they are asked to just listen). The goal is to help students to develop empathy and care for the stakeholders; understand unconscious biases and invisible privileges; and take social responsibility. Additionally, it is expected that this research gives students a better understanding to anticipate the future societal interaction and impact of their design so they can maximize the benefits of their innovation and minimize the risks. Students are encouraged to tap into the resources provided in the ELSEE related courses (ENGR 201 - Professional practice and responsibility and ENGR-392 - Impact of technology on society) throughout their engineering program at Concordia University. Because the expectation for this task is that students are just supposed to "listen" and not "talk" (i.e not present their own point of views), 
students are asked to provide reliable references to all the information gathered for this task.

\section{Task \# 3 - Listen to the experts}

For this task, students are asked to identify all (national and international) experts and peers (industries, organizations, research teams, universities, etc.) working on similar projects (or sub-projects). Additionally, students are asked to thoroughly research on the ELSEE related practices of the experts. Typically, students are used to perform research or review of the technical practices of these experts and peers. In this task, they are asked to specifically explore all the ELSEE related R\&D practices, through various sources like any interviews by related personnel or researchers, closely observing related websites, looking at job advertisements, etc. to gain (as much as possible) insight into their professional engineering practices. This helps students to (i) learn from the experts, (ii) gain ideas for their own project, (iii) avoid re-inventing the wheel, and (iv) gain confidence in their choices. Just like in Task 2, the goal in this task is also to just observe and hence students are expected to provide reliable references for all the information researched for this task.

\subsection{Phase 2 - Implementation and reflection}

Phase 2 is conducted in the second semester of the capstone project during the implementation phase. The idea is that in addition (and in parallel) to implementing the best technological decisions for their design, students are also able to implement a design that is sound (as much as possible) from ELSEE aspects. In this semester, students (group wise) are asked to present all six tasks. The two main ideas behind the presentation of all six tasks together is (1) to push students to have a well-connected ELSEE related story of their research, choices, limitations, and reflections, and (2) identify and discuss any areas in all six tasks which need to be strengthened before students submit the final report. All six tasks (can be the revised version of first three tasks submitted in the mid-term report) are written in the final report as a well-connected story. The three tasks that students are expected to do in Phase 1 are as follows:

\section{Task \# 4 - Your choices}

In this task, based on their research (about related stakeholders, needs and expectations of the stakeholders, engineering failures, ELSEE related R\&D practices, etc.) and knowledge (gained in the professional skills courses taken throughout the program), students are asked to: 1) Describe the steps needed to make their project more ELSEE compliant, 2) Incorporate (as much as possible) these necessary steps in their design, and 3) Discuss the constraints in case it is not possible to implement a certain option. For example, due to limited resources (including time, budget, etc.) or scope, students may still be using a less environmentally friendly material. This is the step where students acknowledge and discuss their choices and limitations.

\section{Task \# 5 - Your confidence in your choices}

This task in some ways is the reflection of the choices discussed in Task 4. The important aspect here is that students are asked to push themselves to go one step ahead of their research (Tasks 2 and 3) and provide evidence, in the form of a research articles, social science theory, or something similar to discuss why given their limitations and choices, they have made a good decision and judgement. In this task, students are once again expected to back up their arguments by evidence instead of just giving their opinions.

\section{Task \# 6 - Reflection}

While Tasks 1 through 5 focuses on pushing students to research and analyze the possible future ELSEE impact of their capstone project and hence implement/incorporate necessary actions, Task \# 6 encourages students to now reflect on their learning of the importance of (i) understanding, (ii) acknowledging, and (iii) incorporating these aspects in the engineering design process. For this discussion, the author has adopted the following definition of critical reflection: "We define 'reflection' as referring to critical reflection, or bringing unconscious aspects of experience to conscious awareness, thereby making them available for conscious choice. This critical reflection is crucial to both individual freedom and our quality of life in society as a whole, since without it, we unthinkingly adopt attitudes, practices, values, and identities we might not consciously espouse. Additionally, reflection is not a purely cognitive activity, but is folded into all our ways of seeing and experiencing the world. Unconsciously held assumptions are not things we rationally know; they are part of our very identity and the ways we experience the world. Similarly, critical reflection does not just provide new facts; it opens opportunities to experience the world and oneself in a fundamentally different way. Even in mundane activities such as shaving one's legs, shopping for meat products, or navigating busy urban streets, critical awareness of feminism, factory farming, or racial issues alters our perception and interpretation of what is going on around us and the implications of our actions" [8, p. 50]. This reflection activity is divided into two parts: Reflection on the final design and reflection in general on the importance of understanding ELSEE impact of any technological innovation. 
For the reflection on the final design, students are asked to:

- discuss which alternative ELSEE related choices were available (for example, choice of material, safety measures, etc.) to them and explain why a particular choice was preferred. This forces students to think of other alternatives, if they had not considered them yet. Additionally, this exercise pushes the students to understand and reflect that sometimes there is not one right option available when social issues are involved unlike the mathematical solutions.

- explain a plan to communicate (if needed) their ELSEE related choices to various stakeholders (researchers, decision makers, media, public, customers, etc.) and communities (scientific, technical, and social) to avoid any future conflict or opposition and to enhance the acceptability of their proposed design. The hope is that this exercise helps our students to understand their social responsibilities and learn to communicate with the society (i.e., the stakeholders)

- reflect on any changes in the final design as compared to the initial plan where technical design decisions were influenced by the ELSEE considerations.

- Reflect on how their design can be changed (if needed) as the socio-economic or other circumstances of the current potential end user changes, e.g., they get old, they have more money, less money, moved to a different city, etc. This helps students to reflect on the long-term success of their design.

- Reflect on the (ELSEE related) risks they are taking and (ELSEE related) assumptions being used.

For the reflection on the importance of understanding ELSEE related issues in a design process, students are asked to reflect on:

- the importance of ethics and societal considerations in the practice of engineering design.

- the habits of thinking as a professional engineer?

- What is a "design failure" from ELSEE point of view. For this students are encouraged to brainstorm that if the design is technically sound, what factors can still cause resistance in the acceptability of the design in the society and hence lead to design failure.

This whole task is mainly reflection. Students are encouraged to go outside their comfort zone to (i) talk about these ideas, (ii) compare and understand the possibilities of conflicting ELSEE related needs of various stakeholders, (iii) broaden their understanding on how to find balance in an engineering design choices, and most importantly, (iv) have a good understanding of ELSEE related aspects that lead to an engineering design failure despite being technically sound. Students are not forced to find one right answer. The hope is that through this reflection our graduating engineers will have a well thought of active awareness of the importance of taking care of ELSEE related issues for the long-term success of an engineering design.

\section{AN OVERVIEW OF WHAT OUR STUDENTS ARE LEARNING FROM THIS EXERCISE}

Mechanical engineering and Electrical and computer engineering students' reflections on habits of thinking as a professional engineer and definition of engineering failure were analyzed to get a sense of what is the take away of our students through these ELSEE related tasks.

\subsection{Habits of thinking as a professional}

Students' reflections on habits of thinking as a professional at the end of these six tasks reflected that this exercise is helping them to understand that being an engineer is more than just being technically sound. A few examples of students' reflections are:

1. "Anything we design as engineers has to be done by thinking about the impact we leave on future generations."

2. "One of the most important habits include putting oneself in perspective of different individuals of the community. For example, an engineer must put themselves in the shoes of people with reduced mobilities, people with disabilities, those of visible minorities, etc. By doing so, the designs of any given project will be more likely to consider ELSEE aspects. Furthermore, an engineer must take responsible risks. Most engineers in their field tend to be innovative and think outside of the box, which is not considered unethical; however, their innovative ideas must still ensure the safety and health of the general public."

3. "No matter the endeavor, the ethics and societal considerations put forth by an engineer are of the utmost importance. From conceptualization to realization, product design and development must take into account the effects it will or potentially can have on society. Without ethical and legal standards, new products can pose dangerous health risks to the general public or could be used improperly and have an unwanted negative impact. Ethics and society are not mutually exclusive and must be considered as a whole to make the appropriate decisions when conducting an iterative design process. Thinking like a professional entails more than just knowledge on the subject matter, it requires a keen ability to consider the possible residual effects of your work, and adjusting 
accordingly. The consideration of the core aspects of ELSEE should come second nature and constantly be revisited with each step in an iterative process."

4. "Professional habits involve continuously questioning why the reasons behind implementing or not implementing certain things, questioning who the solution/design is affecting, and if other groups are affected by the design."

5. "Thinking as professionals means that we are required to think of more than just our pocketbooks; we must always consider the implications of what we are designing and know that as professionals we have a duty to end or pursue technologies that can hinder or benefit society as a whole."

6. "To be aware of your own biases, so that you consider as many aspects of the impact of your work, while taking into consideration important factors that you are prone to overlooking."

7. "This project has taught us to consider the environmental impact our products have and to design products to have minimum impact on the environment and to utilize renewable energy sources."

8. "Taking responsibility of the product being designed and anything that can go wrong with it."

\subsection{Design Failure}

From the reflections on design failures, it was observed that most of the students were able to think beyond the technical success of a technology. A few examples of the definitions of design failure given by students are:

1. "If any risk is posed to the user, builder or even the designer, it would be a failure. If health, safety and legal negligence occurred during design process, it qualifies as design failure. Such malpractice can result in injury or death of those involved or even financial damages to stakeholders."

2. "When speaking of design failures, there are several aspects that lead to such a label. For one, a product is considered a failure if it poses a risk to the health and safety of the user and/or surrounding persons. Secondly, a product that does not meet the needs/requests of the client is also considered a failure. This not only disappoints the client but also creates a bad reputation for the company the engineer is working for. Third, a product that can only be used in certain circumstances is considered a failure as well. An example of this is a walker that functions as intended on smooth hardwood floors; however, outside, on rough terrain, the walker is harder to operate by the user. Finally, if a product is not accessible to all, it is deemed a failure. This goes back to thinking as a professional and putting oneself in perspective of the users. The product must be functional and available for a broad spectrum of individuals. In conclusion, there is a very important relation between engineers and society, and it is the duty of the engineer to ensure the wellbeing of the society."

3. "As such, a more definitive interpretation of "design failure" was acquired. In fact, as future professional engineers, it was primordial to understand that "design failure" is an equal portion technical (efficiency, operation, etc.) as it is non-technical (compliance with ELSEE)."

4. "it is essential to understand that a failed design does not only entail a subpar execution of scientific knowledge or flawed mathematical modelling, but a demonstrated negligence for the non-technical aspects as well. A flawless design is not truly flawless if it does not meet the expectations and demands of the law and public. For example, if a product is in direct ethical and legal violations, no matter how ground-breaking the final product, these issues could potentially prohibit its release into the market, effectively."

5. "When defining "design failure" the obvious situation in which a product or device fails to meet its functional objectives or requirements come to mind. However, design failures extend far past this. Incidences where a product or device meets its specific objective but create health risks and reduces the quality of life are also design failures. Furthermore, should the product or device produce negative financial results or even destabilize the financial situation of a company are also design failures, regardless if they meet their technical objectives. Finally, should a product or device be fully functional on all technical aspects but ultimately result in permanently damaging the company's reputation upon release or throughout time are also products that should be considered as design failures as this result is never desirable and is the most detrimental outcome possible for the company".

6. "In the team's opinion, a product designed using the "I" methodology and without taking into consideration most of the population is considered a design failure."

7. "We believe that a project that does more harm than good for society as a whole would characterize as a failed project."

\section{OTHER DETAILS AND CHALLENGES}

All capstone teams from most engineering departments in Concordia University (Electrical and Computer Engineering; Mechanical, Industrial, and Aerospace Engineering; and Building, Civil, and Environmental Engineering) are required to include all these tasks in their capstone project report. Since each project is very unique, no set rubric is yet developed to evaluate all teams under one criterion. For the moment, main focus of the grading is (i) the amount of research each team has done to understand all possible ELSEE related failures and experts' R\&D practices, (ii) each team's thought processes about ELSEE related decisions, and (iii) quality of the reflection in Task 6. The author understands that quality is a broad 
term that also needs to be further explored, however, for the moment, quality corresponds to the depth of understanding and clarity of the task. Another challenge at the moment is to help students see this whole exercise as an integral part of the capstone and not as an "appendix" that they are writing for the sake of checking off professional skills related "graduate attributes". Additionally, for some purely research-based capstone projects or very specific projects (for example an upgrade of a part of a machine to be used in just one particular lab in the University for teaching purposes) sometimes it gets challenging to research (and hence write) on rich discussions on the societal impact.

\section{FUTURE PLANS}

This effort is just started at Concordia University at the capstone level. For the future, we intend to analyze student responses, design choices, and critical reflections to identify the areas and topics that can be further incorporated throughout the program, so that the students' concepts and design thinking related to ELSEE aspects can be further strengthened before they start their capstone projects. Additionally, we definitely intend to identify other courses (including design courses in first, second, and third years) where this exercise (or some pieces of it) can be introduced. Furthermore, as already mentioned in the introduction, one of the objectives of this article is to open up the discussion and identify possible collaborations around this work. Lastly, we hope to develop a rubric that can be used not just to better assess students' learning of ELSEE aspects in capstone but can also be used in other engineering courses as a tool to assess professional skills.

\section{References}

[1] D. H. Guston and D. Sarewitz. (2002). "Real-time technology assessment. Technology in society, vol 24(1-2), pp. 93-109.

[2] D. Perkins, "Making learning whole: How seven principles of teaching can transform education": John Wiley \& Sons, 2010.

[3] M. Simoni, E. Andrijcic, B. Kline, and A. Bernal, "Helping undergraduate students of any engineering discipline develop a systems perspective," In INCOSE International Symposium, 2016, pp. 495-511.

[4] R. H. Todd, C. D. Sorensen, and S. P. Magleby, "Designing a senior capstone course to satisfy industrial customers," Journal of engineering education, vol 82(2), pp. 92-100, 1993.

[5] J. L. Hess, J. Beever, C. B. Zoltowski, L. Kisselburgh, and A. O. Brightman, "Enhancing engineering students' ethical reasoning: Situating reflexive principlism within the SIRA framework," Journal of Engineering Education, vol. 108(1), pp. 82102, 2019.

[6] D. J. Corple, C. B. Zoltowski, M. Kenny Feister, and P. M. Buzzanell (2020), "Understanding ethical decision-making in design," Journal of Engineering Education, vol. 109(2), pp. 262-280, 2020.

[7] J. V. Farr, M. A. Lee, R. A. Metro, and J. P. Sutton, "Using a systematic engineering design process to conduct undergraduate engineering management capstone projects," Journal of Engineering Education, vol. 90(2), pp. 193-197, 2001.

[8] P. Sengers, K. Boehner, S. David, and J. J. Kaye, "Reflective design" in Proceedings of the 4th decennial conference on Critical computing: between sense and sensibility, pp. 49-58, 2005. 